\title{
A metrópole em Lúcio Cardoso: uma visão expressionista
}

Teresa de Almeida

Universidade Presbiteriana Mackenzie

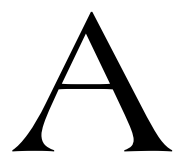

maneira exasperada como Lúcio Cardoso (1912-1968) aborda a cidade do Rio de Janeiro em suas novelas, Inácio (1944) e $O$ enfeitiçado (1954), é magistral. São imagens produzidas pela escritura cardosiana impregnadas de estranheza, em que predominam a distorção e por vezes o grotesco, evocando para o leitor aspectos da estética expressionista. De tal manifestação artística que tendo nascido nas primeiras décadas do século atual, como se sabe, na Alemanha, anunciaria ao lado de outras vanguardas a modernidade, e cujo cinema viria a influenciar com seus temas e clima sombrio a criação do film noir principalmente nos Estados Unidos.

Exemplificando, ao descrever como se processa a "apreensão da cidade" por cineastas vinculados a esse movimento artístico, em seu livro De Caligari a Hitler, o ensaísta Siegfried Kracauer parece nos remeter a algumas das narrativas de Lúcio Cardoso; nas quais, a representação da metrópole se mostra caracterizada em determinadas cenas por uma espécie de agressividade e desordem nela reinante, porém que tanto fascina seus protagonistas.Vê-se, pois, em Kracauer:

Tomadas de carros correndo, fogos de artifício e multidōes formam, junto às tomadas de uma montanha-russa, um confuso conjunto... Através desta engenhosa seqüência de cortes de montagem, a rua é definida como uma espécie de parque de diversōes, isto é, como a região do caos. ${ }^{1}$

E vê-se igualmente em Lúcio Cardoso, em Inácio, por exemplo, a referência à rua com a aglomeração de pessoas ocupando um lugar de destaque no campo visual do espectador: "Assim chegamos à Feira de

${ }^{1}$ KRACAUER, 1988, p. 145. 
Amostras. As mesmas luzes e as mesmas fisionomias que eu vira há pouco, perambulando em todos os cantos da cidade, faces ávidas de esquecimento e diversão a qualquer preço." 2

Assim, pode-se assinalar que ao se falar aqui de expressionismo num escritor como Lúcio Cardoso - conhecido especialmente pela autoria do magnífico romance Crônica da casa assassinada (1959) - e dotado de um estilo exaltado, o termo é empregado à primeira vista num sentido universal. Correspondendo este à subjetividade exacerbada ou à expressão agressiva da emoção, existentes em obras artísticas de épocas diversas. Mas trata-se também ao focalizar a metrópole captada por esse romancista, de se apoiar sobretudo em princípios relativos à estética expressionista no domínio das artes visuais (cinema ou pintura) extraídos de livros como o de Kracauer, há pouco mencionado, o de Lotte Eisner, $O$ ecran demoníaco, Expressionismo de R. S. Furness ou $O$ expressionismo de Roger Cardinal.

Além disso, convém lembrar que Lúcio Cardoso foi cinéfilo na juventude e admirador, em particular, do cinema expressionista com seus grandes realizadores como Fritz Lang, Robert Weine e Murnau. Ainda fez incursões no cinema, como diretor e roteirista, e que embora frustrantes devido a uma série de limitações provocadas pelas condições precárias da indústria do cinema no Brasil - possibilitaram-lhe a experiência suficiente para refletir com justeza a propósito das relações entre a linguagem cinematográfica e a literatura. Vejam-se essas reflexões em seu Diário, em 1949, no período em que dirigia o filme que permaneceu inacabado, $A$ mulher de longe:

Mais uma vez, trabalhando hoje, senti que travellings, panoramas e longshots nada mais são senão capítulos, frases, balbucios do mesmo romance que não se conclui nunca e que, através das imagens procura transmitir sua fantástica existência. ${ }^{3}$

São pois as novelas Inácio (1944) e O enfeitiçado (1954) do romancista, de alta qualidade estética e que não tendo sido valorizadas o bastante até o momento presente, que tratam do tema da grande cidade de modo crucial.

${ }^{2}$ CARDOSO, 1969, p. 71.

${ }^{3}$ CARDOSO, 1970, p. 18. 
Não por acaso três dessas novelas voltadas para a metrópole, incluindo as duas mencionadas, foram reunidas após a morte do escritor, em 1968, numa coletânea intitulada Três histórias da cidade (a terceira é $O$ anfiteatro). Contrapondo-se essas às outras narrativas, de sua autoria, cuja ação se desenrola no interior do país, compondo Três histórias da província (1968).

Em Inácio e $O$ enfeitiçado principalmente, há "tomadas" do Rio de Janeiro com seus bairros populares, em geral, ruas, botequins e prostíbulos. E existe sobretudo a visão alucinada dos narradores em ambas narrativas, apreendendo fragmentos da grande cidade, em particular, à noite, ou quando esta irrompe provocando o surgimento da iluminação artificial.

A metrópole desponta para o leitor, em flashes muitas vezes, caótica, misteriosa ou até fantasmagórica. É como se ela fosse ao mesmo tempo um lugar concreto, ocupando posição precisa num mapa de geografia, e uma região onírica, cujas dimensôes e limites parecem alterar-se de forma monstruosa ou dissolver-se de acordo com o estado emocional das personagens, frequentemente devoradas pela angústia. Sem dúvida então na grande cidade a solidão da personagem cardosiana se adensa, voltada com freqüência para uma espécie de monólogo ou de discurso interior que lembra certas personagens de Dostoievski, autor considerado precursor do Expressionismo. Como Rodion Romanovich Raskolnikov, por exemplo, em Crime e castigo, que perambula com a consciência culpada pelas ruas escuras de São Pertersburgo, metrópole demoníaca, atingida pelo irreal com suas meretrizes, mendigos e indivíduos suspeitos.

Acerca da desmedida, do estilo hiperbólico do romancista na criação desse Rio de Janeiro marcado pelo demonismo ou mesmo dostoievskiano observando que Lúcio foi considerado um autor dostoievskiano pela crítica brasileira ao lado de Octávio de Faria e Cornélio Penna a partir dos anos 30 - convém observar que Mario Carelli em Corcel de fogo ao abordar o primeiro livro cardosiano, o romance Maleita (1934), penetrado de barroquismo, com sua miséria e violência invadindo as terras do sertão, refere-se com agudeza à "maneira expressionista" do autor ali já prefigurada e que não cessaria de se afirmar em todo o resto de sua obra.

Nas novelas Inácio e $O$ enfeitiçado, com a narração em primeira pessoa - fator que propicia sem dúvida a irrupção da subjetividade na captura dos acontecimentos - vêem-se os protagonistas, com freqüência em estado febril, como no conto $O$ homem da multidão, de Edgar Allan Poe, em errâncias 
obsessivas ou possuídos por uma espécie de loucura deambulatória. Caminhando através de ruas ameaçadoras ou com aglomerações. Aqui certamente evocamos o estudo de Walter Benjamin a respeito dos temas urbanos em Baudelaire; e desse célebre conto de Edgar Allan Poe, traduzido pelo poeta francês, em que um narrador-protagonista vem a perseguir um passante em suas andanças pelas ruas, praças e vielas de Londres, sob focos de luzes de lampiões, e deliberadamente perdendo-se na multidão.

Roger Cardinal comentando a respeito da grande cidade na obra do autor de Fleurs du mal a relaciona com o Expressionismo de alguma maneira: "Os temas urbanos podem ser vistos como consequiência de uma estética do choque, que remontam a Baudelaire e suas impressóes de uma Paris decadente. Esses temas são retomados com tal entusiasmo nem tanto porque o Expressionismo tivesse com eles uma afinidade específica (...) mas porque a cidade é o local predestinado da urgência. Com suas ambigüidades e excessos, sua capacidade de exacerbar uma ânsia de naturalidade (...) a cidade ultrajou e hipnotizou um grande número de artistas." ${ }^{4}$

No tocante ainda às ruas ameaçadoras, permitindo nesse tipo de narrativa a inclusão de cenas angustiantes de perseguição, é pertinente observar o mesmo ensaísta em $O$ expressionismo: "A associação feita entre ruas e ameaças desenvolve-se rapidamente no período expressionista, e acabou por dar origem a um cenário típico, traço indispensável ao film noir hollywoodiano - o estereótipo inclui asfalto brilhando sob a chuva, tráfego anônimo, prostitutas perambulando (...)" 5

Prosseguindo, observa-se que na primeira novela, Rogério Palma habitando numa pensão barata com moradores de aspecto ridículo, com um comportamento atingido pela ilogicidade - como tantas outras personagens de Lúcio Cardoso percorre os bairros à procura do pai, Inácio Palma. Este com o seu sinistro rosto de "boneca", que parece não envelhecer, vestindo continuamente o casaco xadrez, fora de moda. Enquanto n' $O$ enfeitiçado, numa inversão de focos narrativos, é Inácio quem buscará o filho desaparecido de sua vida pelas trilhas da grande cidade. Escrevendo em suas memórias: "Como outrora, ele tanto me procurara através das ruas (...) agora eu o procurava - e pelas mesmas ruas...”.

${ }^{4}$ CARDINAL, 1984, p. 89.

${ }^{5}$ CARDINAL, 1984, p. 87. 
Nesta segunda novela, escrita por Lúcio dez anos após a narrativa anterior, Inácio envelhecido e pobre procura, portanto, o filho extraviado na névoa de paisagens urbanas e hostis: "Eu próprio, com o cuidado e a perícia de quem já havia experimentado a densa e morna fumaça desses lugares, desci aos antros noturnos do Rio, na esperança de encontrar num deles aquele que eu procurava”. É uma busca desesperada que de algum modo se efetua não somente pelos lugares da metrópole e do subúrbio como também pelos caminhos do tempo e no interior da própria personagem.

Daí a presença de vários depoimentos para Rogério acerca da mãe e do pai numa tentativa vã de se reconstituir o passado. E a das memórias de Inácio, na novela seguinte. Tentativas estas de se recapturar as pessoas amadas - desaparecidas no espaço temporal e físico caracterizado pelo caos constituindo uma forma de se readquirir a própria essência mais profunda. Perdendo o filho nos antros do Rio, Inácio sente escapar-lhe para sempre a identidade, como se ele próprio se metamorfoseasse numa figura fantasmática. É o que lhe diz a cartomante Lina de Val-Flor numa de suas consultas: "O senhor não está vivo (...) o senhor não passa de um espectro.”6

Quanto ainda às outras personagens do ficcionista - tocadas pela loucura e o irrealismo em sua construção - na primeira novela há o gordo e caricato Lucas Trindade, apaixonado por Stela e odiando intensamente Inácio, que fora casado com esta última. E pode-se indagar aqui, nesta impossibilidade de se apreender a verdade dos fatos, em textos tão penetrados de ambigüidade: Stela, mãe de Rogério Palma, depois de haver sido rica e respeitável, esposa de Inácio um afortunado "homem de negócios”, teria se transformado na prostituta que provocara rivalidades com sua beleza e o jeito poderosamente zombador?

E para se tomar contato com uma das outras faces da mesma Stela, assiste-se, num dos trajetos de Rogério pela cidade em ambientes de pensões e corredores exíguos, ao seu encontro num quarto sórdido com o cadáver dela, velado por Lucas Trindade. Encontro este expresso para o leitor de forma teatral e quase absurda. Porque neste cenário iluminado apenas por uma luz baixa e revestida com um papel verde, ao lado da defunta coberta por um lençol e calçando meias pretas, vêem-se espalhados pelo chão poeticamente inúmeros chapéus femininos ornados com flores e pássaros.

${ }^{6}$ CARDOSO, 1969, p. 288. 
Em passagens como esta, mais do que nunca, o Lúcio Cardoso romancista revela também que é cineasta, cenógrafo e que parece dirigir sua narrativa para outras fruições estéticas que não sejam aquelas especificamente literárias.

Aliás, ainda convém notar a respeito do nome dessa personagem, Stela - existente sobretudo na memória e depoimentos das demais criaturas da novela Inácio - que ele parece corresponder a uma imagem absoluta de inocência para os olhos apaixonados de Lucas, conforme este a caracteriza para Rogério: "Era uma santa". Mas também este mesmo nome Stela, opondose ao outro sentido, conota ainda o de "astro" ou "estrela" cintilando no domínio escuro da devassidão, segundo o relato de uma prostituta para Rogério Palma: "(Ela, Stela) Parecia um astro, cintilava coberta de jóias, ria, bebia, entregava-se a todos, de olhos fechados. (...) Tornou-se célebre como a prostituta mais cruel do Rio de Janeiro."

Assim, de maneira marcante, num espaço fechado, transparecem elementos expressionistas que também se encontram na configuração do grande espaço físico da cidade, ao serem aqui enfocados num ambiente de obscuridade a presença da morte ("Agora ela está morta. Acaso você compreende o que significa morrer?", pergunta Lucas a Rogério), do grotesco (as meias pretas se destacando de modo insólito nos pés da defunta), e do terror (a iluminação no rosto desgastado da morta que fora, talvez, pura ou prostituta).

E Rogério, em Inácio, prosseguindo na busca do pai pelo Rio de Janeiro, nomeia ao longo de seu relato os bairros (Lapa, com seu ar pestilento e viciado, Cinelândia, Copacabana, Praia de Santa Luzia...) pelos quais perambula, nessa espécie de viagem constituída de idas e vindas obsessivas a determinados lugares. Igualmente em $O$ enfeitiçado, tais nomes e outros ainda se reiteram (novamente Lapa, Centro, Gamboa, Saúde, Meyer, e ainda restaurantes e hotéis suspeitos como Progresso do Meyer, Bar da Europa, Hotel da Lanterna, A Pastora de Nápoles...)

Assim os cenários ou o espaço físico do Rio de Janeiro, embora não propriamente descritos pelo autor, mas nomeados com constância, revelamse altamente intrigantes em sua configuração. Há várias ocorrências de lugares envolvidos pela névoa ou penumbra, exteriores ou interiores, principalmente em $O$ enfeitiçado, como numa atmosfera de sonho ou pesadelo. Porque muitas são as ruas ou os antros, vielas ou restaurantes de

${ }^{7}$ CARDOSO, 1969, p. 66. 
baixa qualidade, emergindo para o leitor-espectador num tom acinzentado de sombra ou fumaça, povoados por entes pálidos e estranhos sugerindo a presença do vampirismo ou do Mal apoderando-se do mundo, tema este abordado por Lúcio Cardoso em outras suas obras, como $A$ luz no subsolo (1936) e $O$ desconhecido (1940).

A propósito desse aspecto noturno e do tom apocalíptico das suas narrativas, é interessante citar Otto Maria Carpeaux, em História da literatura ocidental, ao estudar as manifestaçôes do Expressionismo nas primeiras décadas do século XX: "Nunca houve movimento literário mais noturno do que este, que vencera com seu profeta pictórico o sombrio norueguês Edvard Munch. Uma noite perpétua, só interrompida por raios apocalípticos que anunciaram profeticamente - em 1910 e 1911 - o fim do mundo de então". ${ }^{8}$

Exemplificando, acerca do clima constituído de penumbra e de irrealidade em Inácio, na ótica transtornada de Rogério, sentindo-se perseguido pelo pai: "Olhei para trás de novo, e mais uma vez convenci-me de que realmente era ele. Então não me contive e, sob a pressão da névoa, da sombra projetada pelos grandes edifícios e do meu próprio terror..." , " $\mathrm{E}$ tudo ali, naquele momento, causava-me terror, desde as verduras amontoadas, que assumiam aspectos horripilantes, até os vultos dos vendedores, ainda meio indistintos à luz da madrugada". ${ }^{10}$

E sobretudo na segunda novela, $O$ enfeitiçado, as ocorrências da relação da personagem com a grande cidade noturna se mostram fecundas. Inácio registra em suas memórias: "Ninguém saberá jamais o que é a noite para os notívagos: eles se roçam nela, embriagam-se com sua cálida essência (...)", ${ }^{11}$ "aquela mulher de azul ali, no canto, com uma grande rosa branca no ombro (...) de olhos semi-cerrados e através de uma nuvem de fumaça, tenta envolver-me num movimento de sedução?". Ou mesmo "Os notívagos roçavam por mim nas rampas e nos becos, prosseguindo no seu destino de sombras." 12

${ }^{8}$ CARPEAUX, 1966, p. 3096.

${ }^{9}$ CARDOSO, 1969, p. 57.

${ }^{10}$ CARDOSO, 1969, p. 58.

${ }^{11}$ CARDOSO, 1969, p. 241-242.

${ }^{12}$ CARDOSO, 1969, p. 281. 
Finalmente, em $\mathrm{O}$ enfeitiçado, o elemento neblina ou penumbra com a sua tonalidade cinzenta se metaforiza de modo significativo na linguagem artística de Lúcio Cardoso, parecendo recobrir com sua ampla ausência de luz ou ausência de Deus, pode-se acentuar - todo o significado da existência humana: "um imenso véu de neblina e tédio se estende sobre o mundo. Mundo mofado, mundo de sono e odiosa quietude." ${ }^{13}$ E diante da relevância deste tipo de iluminação ou de coloração nos textos cardosianos - sombria com efeitos inesperados de luz, como se verá adiante - lembramos de Lotte Eisner ao abordar o tema do "claro-escuro" no cinema expressionista com a presença do sobrenatural. Escreve a autora em $O$ ecran demoníaco:

Nenhum realizador (como Murnau em O Fausto, 1926), nem mesmo Lang, soube fazer surgir tão magistralmente o sobrenatural em pleno estúdio; será ainda um manto do demônio que cobre toda a cidade com as suas dobras enormes, ou é apenas uma nuvem gigantesca que pesadamente paira sobre ela? Irão as trevas diabólicas devorar a claridade divina? ${ }^{14}$

Em Inácio, há referências aos letreiros luminosos ofuscando o rosto adolescente de Rogério em suas andanças pela Lapa, acompanhado do caricato Lucas Trindade. E ao néon deformando os seres nas ruas tornandoos subitamente monstruosos. Existem ainda as luzes das espeluncas, das Feiras de diversôes, e mesmo com raridade a luz violenta do sol de Copacabana no dia azul perfurando o clima de penumbra da narrativa.

Mas surge também, por mais de uma vez, nos "cenários" da primeira novela de Lúcio Cardoso, em corredores lúgubres e gordurosos de casas de cômodos, uma lâmpada no alto, baça, como um olho sinistro e cujo objetivo parece ser o de acentuar o enigma e a penúria do lugar. Ou antes, prenunciando para as personagens que ali penetram a presença do grotesco e da morte. Ou mesmo do homicídio. Porque após o assassinato de Lucas numa dessas espeluncas, por Rogério a mando de Inácio, pai e filho atravessam a cidade no carro num movimento alucinante. As "tomadas" ou os planos sucedem-se uns aos outros no campo visual do fugitivo:

\footnotetext{
${ }^{13}$ CARDOSO, 1969, p. 255.

${ }^{14}$ CARDOSO, 1969, p. 167.
} 
(...) eu via as luzes desfilarem através dos vidros descidos, letreiros grandes e pequenos, coloridos, rápidos (...) vertiginosamente como num sonho (...) tudo me parecia irreal, com detalhes de um mundo grotesco e inconsciente. ${ }^{15}$

Em $O$ enfeitiçado, ao conduzir a jovem e pura Adélia, embriagada e com os cabelos desfeitos, pelos becos e vielas que margeiam a estação Central do Brasil, Inácio se sente uma ave de rapina protegido pela noite infernal: "Eu a levava apertada contra o meu peito, como uma ave de rapina segura a presa conquistada." ${ }^{16}$ Numa sugestiva imagem comparativa, Inácio Palma transmuta-se numa figura alada de conotações negativas. Ave de rapina que sugere a presença de forças maléficas ou demoníacas subtraindo a vida dos outros. A esse respeito, o Expressionismo ainda nos oferece uma informação, segundo Lotte Eisner no Ecran demoníaco: "(Dr. Mabuse, 1922, filme de Fritz Lang) tem também contrastes de luz de grande beleza: uma ruela à noite, onde as sombras esvoaçam como aves de rapina”.

Há efeitos plásticos e cinematográficos de sombra e luz também provenientes da noite reverberando no rosto da jovem, sentada ao lado de Inácio no táxi que atravessa a cidade, isolada em seus pensamentos e desejada profundamente por este: "sei que rolávamos pelas ruas frias e iluminadas e que no seu rosto, como num jogo mágico, as zonas claras se sucediam às zonas da escuridão". ${ }^{17}$

Finalmente, afastando-se para o subúrbio onde mora numa pensão lúgubre, Inácio vem a encontrar ali o cenário preparado para o crime, a sua morte, como num palco de teatro. Há toda uma mise-en-scène nessa atmosfera terrivelmente opressiva: as donas da pensão surgem vestidas de forma espalhafatosa com laços e segurando ventarolas, um jato de luz violenta de repente se introduz pela porta aberta onde se encontra o perseguidor de Inácio - a mando da cartomante Lina de Val-Flor cuja filha, Adélia, fora seduzida por este último - com seu capote de soldado e cicatrizes no rosto boçal. Acossado pois dentro da casa, Inácio que já reconhecera com lucidez o absurdo da existência e "que transitara por todas as ruas do mundo", como

\footnotetext{
${ }^{15}$ CARDOSO, 1969, p. 114.

${ }^{16}$ CARDOSO, 1969, p. 322-323.

${ }^{17}$ CARDOSO, 1969, p. 267.
} 
ele mesmo o confessa, aguardará a morte, transpondo o limiar (através de um laço pronto para o enforcamento) em direção ao Nada.

Marcadas constantemente pelas imagens do terror ou do crime, essas personagens são conduzidas, em geral, a gestos desmesurados como crises de risos ou agressões físicas em locais públicos, muitas vezes diante das aglomerações. Esse comportamento desprovido de lógica ocorre principalmente em Inácio, cujo ponto de vista é o de um adolescente em estado freqüente de delírio (Inácio nunca se esqueceria daquela imagem do filho, Rogério, na estação de trem gargalhando com rosas junto ao peito) e que nas páginas finais, para surpresa do leitor, mostra-se internado num manicômio.

Assim como na tragédia, o desfecho a que conduzem as atitudes desvairadas dessas personagens parece, desde o início, prefigurado de modo inexorável. Lúcio Cardoso é pois um autor que retrabalha a noção trágica deixando de lado o rigor solene, hierático, quase geométrico do gênero, injetando nele um grito de revolta das criaturas em conflito visceral com a sociedade moderna. Tal como o célebre quadro $O$ grito do norueguês Edvard Munch, repleto de solidão.

E não por acaso vê-se Inácio, numa das seqüências finais d' $O$ enfeitiçado, contemplando, à noite, a cidade enfumaçada do Rio de Janeiro com seus prédios, lojas, salas de assembléias, conselhos, fortalezas e prisões. Lembrando Lotte Eisner que escreveu em Ecran demoníaco "O expressionismo não vê, tem visões", observa-se que a paisagem urbana surge ali, mais do que nunca, num tom quase apocalíptico, como o prolongamento psíquico do protagonista. Pois Inácio pressente fortemente, num estado de alucinação, a demência movendo-se debaixo das construções: "Surda, como uma vaga soterrada, a loucura viajava insone sob a laje dos edifícios." 18

${ }^{18}$ CARDOSO, 1969, p. 297. 


\section{Referências Bibliográficas}

ARCO E FLEXA, Teresinha de Almeida. Lúcio Cardoso e Julien Green: transgressão e culpa. São Paulo, 1990. 2 v., 378 p. Tese (Doutorado em Língua e Literatura Francesa) - Faculdade de Filosofia, Letras e Ciências Humanas, Universidade de São Paulo, 1990.

. Marcas do texto: Julien Green e outros. In: CARDOSO, Lúcio. Crônica da Casa Assassinada. Ed. crítica coord. por Mario Carelli. España: Archivos/ CSIC, 1991. (Col. Archivos, 18).

CABAU, Jacques. Edgar Poe par lui-même. Paris: Seuil, 1960.

CARDINAL, Roger. O expressionismo. Trad. Cristina Barczinski. Rio de Janeiro: Jorge Zahar, 1984.

CARDOSO, Lúcio. Três histórias da cidade. (Inácio, $O$ anfiteatro e $O$ enfeitiçado). 2. ed. Rio de Janeiro: Edições Bloch, 1969.

. Diário Completo. Rio de Janeiro: José Olympio/INL, 1970.

CARPEAUX, Otto Maria. História da Literatura Ocidental, Vol. VII. Rio de Janeiro: Edições O Cruzeiro, 1966.

EISNER, Lotte. O ecran demoníaco. Trad. João Rubens Belo. Lisboa: S.I., s/d.

FURNESS, R. S. Expressionismo. Trad. Geraldo G. de Souza. São Paulo: Perspectiva, 1990. (Col. Elos).

KRACAUER, Siegfried. De Caligari a Hitler. Trad. Tereza Ottoni. Rio de Janeiro: Jorge Zahar, 1988.

\section{Resumo}

Este ensaio analisa aspectos da estética expressionista presentes nas novelas Inácio e O enfeitiçado de Lúcio Cardoso.

\section{Abstract}

This essay analyzes aspects of the expressionist aesthetics presented in the short novels Inácio and O enfeitiçado of Lúcio Cardoso. 